\title{
Titanium granules pre-treated with hydrogen peroxide inhibit growth of bacteria associated with post-operative infections in spine surgery
}

\author{
Acke Ohlin ${ }^{1} \cdot$ Emma Mattsson ${ }^{2} \cdot$ Matthias Mörgelin $^{3} \cdot J_{u l i a}$ R. Davies ${ }^{4} \cdot$ Gunnel Svensäter $^{4} \cdot$ Stéphane Corvec $^{5,6}$. \\ Pentti Tengvall ${ }^{7} \cdot$ Kristian Riesbeck $^{2}$ (i)
}

Received: 24 November 2017 / Revised: 23 April 2018 / Accepted: 26 April 2018 / Published online: 7 May 2018

(C) The Author(s) 2018

\begin{abstract}
Purpose Post-operative infections are relatively common after posterior spine surgery, and there are several observations reflecting different infection complications related to various metals implanted. Here, we selected an array of different bacterial species that are often found in infections associated with orthopaedic implants and tested for inhibition by hydrogen peroxide-treated titanium (Ti-peroxy).

Methods To study the possibility of using Ti-peroxy as an antimicrobial prophylaxis, we developed a protocol for standardized susceptibility testing of bacteria.

Results Importantly, we found that the resulting Ti-peroxy was highly antimicrobial against all aerobic species tested, among others, Staphylococcus aureus and Pseudomonas aeruginosa. Proteus mirabilis was slightly more resistant than, for example, Klebsiella pneumoniae and enterococci. In contrast, anaerobic bacteria Cutibacterium acnes and Parvimonas micra were equally susceptible compared to staphylococci.

Conclusions Our findings suggest that the Ti-peroxy is a promising perioperative antimicrobial strategy that may be highly effective for prevention of post-operative infections. We therefore suggest application of hydrogen peroxide to implants prior to implantation.
\end{abstract}

Graphical abstract These slides can be retrieved under Electronic supplementary material.
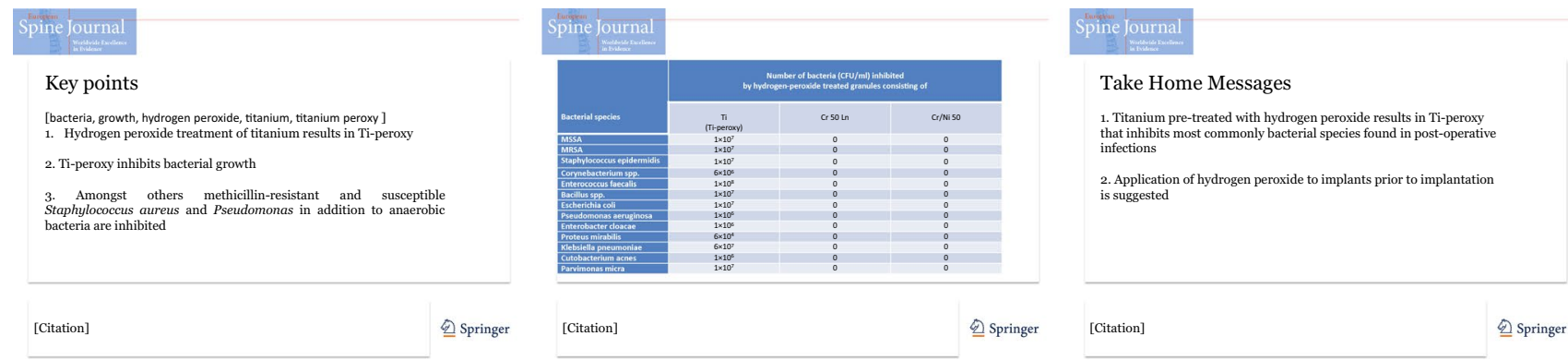

Keywords Bacteria $\cdot$ Growth $\cdot$ Hydrogen peroxide $\cdot$ Titanium $\cdot$ Titanium peroxy

\section{Introduction}

Electronic supplementary material The online version of this article (https://doi.org/10.1007/s00586-018-5619-8) contains supplementary material, which is available to authorized users.

Kristian Riesbeck

kristian.riesbeck@med.lu.se

Extended author information available on the last page of the article
Early and late deep infection after posterior spine surgery with instrumentation is a relatively common complication, often necessitating implant removal. Factors influencing implantrelated infections are multiple: the localization and extension of wound, length of surgery time, blood loss, nutritional status 
of patient, use of perioperative antibiotics, use of pulse lavage and quality of the operative room, e.g. ventilation conditions [1]. The rate of post-operative surgical site infections after spine surgery varies based on patient comorbidities from 0.7 to $4.3 \%$ among patients without risk factors to 2.0 to $10 \%$ in patients with obesity, diabetes and neuromuscular diseases [2]. The rate of late implant-associated deep infection after posterior spinal instrumentation is, however, significantly reduced when using a metal work made from titanium alloy compared with stainless steel [3-5]. In a previous study with a total of 1390 patients, the infection rate was significantly higher in patients that received stainless-steel implants [6]. Infection rate with titanium implants was $3.53 \%$ as compared to $11.56 \%$ with stainless-steel implants $(p<0.0001)$. In yet another investigation $(n=540)$, the infection rate was $1.33 \%$ compared to $4.56 \%$ for titanium and stainless-steel implants $(p<0.0001)$, respectively [7]. The reason for this is not fully understood.

More than 25 years ago, Tengvall et al. reported on the formation of relatively stable titanium compounds formed at Ti-implant surfaces as one explanation of the low infection rate after implantation of dental Ti-screws [8, 9]. Analytical data indicated that those compounds consisted of aqueous Ti-peroxide [10]. The formation of titanium peroxy compounds is due to a chemical reaction of Ti(III) and/or Ti(IV) ions with $\mathrm{H}_{2} \mathrm{O}_{2}$ being released by inflammatory cells. The tissue concentration may be up to $10 \mu \mathrm{M}$ during inflammatory states [11]. Ti-peroxide is subsequently degraded to $\mathrm{TiO}_{2}, \mathrm{H}_{2} \mathrm{O}_{2}, \mathrm{O}_{2}$, and $\mathrm{H}_{2} \mathrm{O}$. The time frame of degradation in vitro is from hours to days [12]. This process probably results in inhibition of early growth and survival of bacteria in the close vicinity of implants with this coating.

The main aim of the present study was to determine the viability of bacteria in the presence of metal granules made from commercial pure titanium (Ti) and "orthopaedic" stainless steel with or without previous treatment with hydroxyperoxide. We hypothesized that hydrogen peroxidetreated Ti granules, hereafter designated Ti-peroxy, would reduce bacterial viability. A series of different microbes, which are well known and often recognized in cultures of specimens obtained at reoperations due to deep late infections after posterior spinal instrumentation $[1,2]$, were included in the study and examined for growth in the presence of Ti-peroxy. Finally, scanning electron microscopy was carried out to visualize the gross appearance of Ti-peroxy-dependent inhibitory activity.

\section{Material and methods}

\section{Bacterial strains and culture conditions}

The different bacterial species examined in the present study are outlined in Table 1. A collection of Cutibacterium acnes isolated from patients with spine and knee joint infections after surgery was also included in our study [13]. This chosen set of both Gram-negative and Gram-positive bacteria was grown according to standard microbiological culture conditions. Briefly, Staphylococcus aureus, S. epidermidis, Corynebacterium renale, C. pilosum, Enterococcus faecalis, Bacillus badius, B. cereus, Escherichia coli, Pseudomonas aeruginosa, Enterobacter cloacae, Proteus mirabilis and, finally, Klebsiella pneumoniae were grown on chocolate agar plates (Oxoid, Waltham, MA). In contrast, the anaerobic species Cutibacterium acnes (previously Propionibacterium acnes) and Parvimonas micra (previously Peptostreptococcus micros) were grown on FAA plates (LabM, Heywood, UK). Aerobic bacteria were grown at $37{ }^{\circ} \mathrm{C}$ in $5 \% \mathrm{CO}_{2}$, whereas the anaerobes were incubated in anaerobic jars at $37^{\circ} \mathrm{C}$.

\section{Preparation of Ti-peroxy}

Sterilized granules $(2 \mathrm{ml})$ consisting of commercially available titanium (size 0.5-1.0 mm) (Koch-Light, Haverhill, UK), chrome $50 \mathrm{Ln}$ (size $0.5-1.0 \mathrm{~mm}$ ) or chrome/nickel 50 (size $0.5-1.0 \mathrm{~mm}$ ) (kindly provided by Pometon, Maeme [Venice], Italy) were included in the study. The chrome $50 \mathrm{Ln}$ and chrome/nickel 50 granules are comparable with stainless steel in orthopaedic implants. Granules were incubated with $5 \mathrm{ml} 30 \% \mathrm{H}_{2} \mathrm{O}_{2}$ for $15 \mathrm{~min}$ at room temperature. Thereafter, granules were washed with $50 \mathrm{ml} 0.9 \% \mathrm{NaCl}$ and dispensed into deep-bottom 96-well plates (Whatman, Maidstone, UK). Granules ( $40 \mu$ l wet volume) were added to each well corresponding to approximately $86 \mu \mathrm{g} \mathrm{Ti}, 188 \mu \mathrm{g}$ Cr $50 \mathrm{Ln}$ or $270 \mu \mathrm{g} \mathrm{Cr} / \mathrm{Ni} 50$.

\section{Analysis of the inhibitory effect of Ti-peroxy on bacteria}

To prepare bacteria, overnight cultures of $E$. coli and $P$. aeruginosa were resuspended in Luria-Bertani (LB) broth (Becton-Dickinson, Franklin Lakes, NJ), whereas the remaining species were resuspended in Brain Heart Infusion (BHI) broth (Becton-Dickinson, Stockholm, Sweden). P. acnes and $P$. micra were diluted in $\mathrm{BHI}+10 \%$ foetal bovine serum (FBS) (Gibco Life Technologies, Warrington, UK) and FA broth (LabM, Heywood, UK), respectively. After resuspension, optical density (OD) 600 was set to 0.1 and 0.5 for aerobes and the anaerobes including Corynebacterium spp., respectively. Thereafter, a tenfold dilution series was made, and $800 \mu \mathrm{l}$ of the bacterial suspensions was added to plates containing various granules. Microtiter plates were sealed with adhesive gas-permeable seals (Thermo Scientific, Waltham, MA) and incubated at $37{ }^{\circ} \mathrm{C}, 5 \% \mathrm{CO}_{2}$ shaking at $200 \mathrm{rpm}$. Anaerobes were incubated in anaerobic jars, $37^{\circ} \mathrm{C}$, shaking at $150 \mathrm{rpm}$. After $24 \mathrm{~h}$ incubation or $7 \mathrm{~d}$ for 
Table 1 Bacterial strains used in the present study

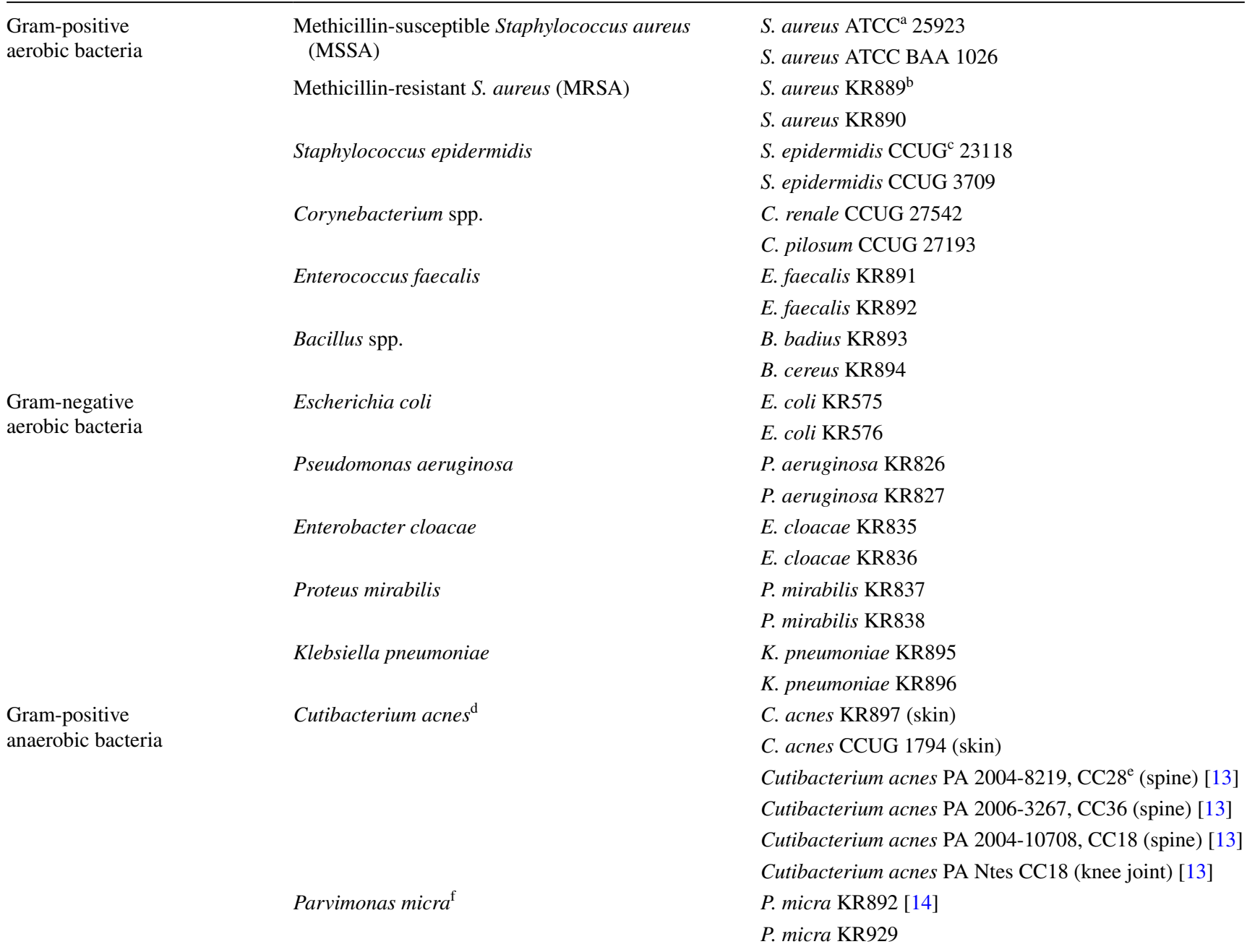

${ }^{a}$ ATCC: American Type Culture Collection, LGC Standards, Teddington, UK

${ }^{b}$ KR; Kristian Riesbeck laboratory, Clinical Microbiology, Malmö, Sweden

${ }^{\mathrm{c} C u l t u r e}$ Collection University of Gothenburg, Sweden

${ }^{\mathrm{d}}$ Previously designated Propionibacterium acnes

${ }^{\mathrm{e}} \mathrm{CC}$; clonal complex as described [13]

${ }^{\mathrm{f}}$ Previously designated Peptostreptococcus micros

anaerobes, $100 \mu \mathrm{l} /$ well was transferred to microtiter plates to measure absorbance at $\mathrm{OD}_{600} \mathrm{~nm}$. In separate experiments, the kinetics of antibacterial activity of hydrogen peroxidetreated Ti granules was determined. Granules were preincubated with $\mathrm{H}_{2} \mathrm{O}_{2}$ and thereafter stored in a closed container before addition to bacterial cultures as described above.

\section{Scanning electron microscopy}

For scanning electron microscopy, specimens were fixed overnight at room temperature with $2.5 \%$ glutaraldehyde in cacodylate buffer, washed with cacodylate buffer and dehydrated with an ascending ethanol series from 50\% (v/v) to absolute ethanol. The specimens were dried in a critical point dryer with carbon dioxide and absolute ethanol as an intermediate solvent. Samples were mounted on aluminium holders, sputtered with $20 \mathrm{~nm}$ palladium/gold and examined in a Philips/FEI XL 30 FESEM scanning electron microscope using an Everhart-Thornley secondary electron detector. Image processing was carried out with the Scandium software (Emsis, Münster, Germany) for simple image acquiring and auto-storage into the Scandium database. All electron microscopic work was performed at the Core Facility for Integrated Microscopy, Panum Institute (University of Copenhagen, Denmark). 


\section{Results}

\section{Titanium peroxy efficiently inhibits bacterial growth}

We chose a large panel of different bacterial species that are commonly found in patients who have undergone spine surgery complicated by deep infection (Table 1) [1]. Two isolates of each species except for Cutibacterium acnes $(n=6)$ were included in the study. Titanium granules were treated with hydrogen peroxide for 15 min followed by washing with saline resulting in a Ti-peroxide. To analyse the inhibitory effect on growth, bacteria were incubated with the Ti-peroxide, and, in addition, hydrogen peroxide-treated $\mathrm{Cr} 50 \mathrm{Ln}$ or $\mathrm{Cr} / \mathrm{Ni}$ was included as controls. The effect of untreated $\mathrm{Ti}$ (without previous exposure of hydrogen peroxide) was also analysed. All granules were supplemented to microtiter plates followed by addition of bacteria in solution.

Hydrogen peroxide-treated Ti granules, i.e. the Ti-peroxy inhibited a large number of bacteria in our experimental set-up (Table 2). Bacterial growth was significantly inhibited in the interval $6 \times 10^{4}$ to $10^{8} \mathrm{CFU} / \mathrm{ml}$ upon exposure to the Ti-peroxy for $24 \mathrm{~h}$ (aerobes) or 7 days (anaerobes). In contrast, $\mathrm{Cr} 50 \mathrm{Ln}$ and $\mathrm{Cr} / \mathrm{Ni}$ that were preincubated with $\mathrm{H}_{2} \mathrm{O}_{2}$ did not interfere with bacterial growth, and with these apparently inert granules, no inhibition was observed as compared to culture media without any granules added. In parallel, untreated Ti granules did not interfere with bacterial growth (results not shown). Proteus mirabilis was the most resistant species, and here more than 1000 -fold fewer bacteria $\left(6 \times 10^{4} \mathrm{CFU} / \mathrm{ml}\right)$ were inhibited compared to, for example, enterococci $\left(10^{8} \mathrm{CFU} /\right.$ $\mathrm{ml})$. Regarding other Gram-negative species, we did not find any large differences in Ti-peroxy-dependent growth inhibition. In parallel, anaerobes including $C$. acnes and Parvimonas micra were both efficiently inhibited by the Ti-peroxy, but not by $\mathrm{Cr} 50 \mathrm{Ln}, \mathrm{Cr} / \mathrm{Ni}$ or untreated Ti. A series of different clinical C. acnes isolated from orthopaedic patients belonging to different clonal complexes (CC) [13] was also tested, but no difference was observed in Ti-peroxy-dependent growth inhibition as compared to C. acnes isolates derived from the skin.

To determine the stability of the Ti-peroxy, titanium was pre-treated with hydrogen peroxide according to the standard protocol, and thereafter, the resulting Ti-peroxy was added to bacterial cultures after different time points. The antibacterial activity of the Ti-peroxy persisted for at least $24 \mathrm{~h}$, but at later time points, the activity decreased, and when the Ti-peroxy had been stored for more than $72 \mathrm{~h}$ at room temperature, no inhibitory effect was observed (data not shown). However, when the Ti-peroxy was stored at $-18{ }^{\circ} \mathrm{C}$, the antibacterial activity was preserved for at
Table 2 Titanium peroxy has an effect on all bacterial species tested

\begin{tabular}{|c|c|c|c|}
\hline \multirow[t]{2}{*}{ Bacterial species } & \multicolumn{3}{|c|}{$\begin{array}{l}\text { Number of bacteria }(\mathrm{CFU} / \mathrm{ml}) \text { inhib- } \\
\text { ited by hydrogen peroxide-treated } \\
\text { granules consisting of }\end{array}$} \\
\hline & Ti (Ti-peroxy) & Cr $50 \mathrm{Ln}$ & $\mathrm{Cr} / \mathrm{Ni} 50$ \\
\hline MSSA $^{\mathrm{a}}$ & $1 \times 10^{7}$ & 0 & 0 \\
\hline MRSA $^{a}$ & $1 \times 10^{7}$ & 0 & 0 \\
\hline Staphylococcus epidermidis ${ }^{\mathrm{a}}$ & $1 \times 10^{7}$ & 0 & 0 \\
\hline Corynebacterium spp. ${ }^{\mathrm{b}}$ & $6 \times 10^{6}$ & 0 & 0 \\
\hline Enterococcus faecalis $^{\mathrm{a}}$ & $1 \times 10^{8}$ & 0 & 0 \\
\hline Bacillus spp. $^{\mathrm{a}}$ & $1 \times 10^{7}$ & 0 & 0 \\
\hline Escherichia coli $^{\mathrm{a}}$ & $1 \times 10^{7}$ & 0 & 0 \\
\hline Pseudomonas aeruginosa ${ }^{\mathrm{a}}$ & $1 \times 10^{6}$ & 0 & 0 \\
\hline Enterobacter cloacae $^{\mathrm{a}}$ & $1 \times 10^{6}$ & 0 & 0 \\
\hline Proteus mirabilis $^{\mathrm{a}}$ & $6 \times 10^{4}$ & 0 & 0 \\
\hline Klebsiella pneumoniae $^{\mathrm{a}}$ & $6 \times 10^{7}$ & 0 & 0 \\
\hline Cutibacterium acnes $^{\mathrm{b}}$ & $1 \times 10^{6}$ & 0 & 0 \\
\hline Parvimonas micra ${ }^{\mathrm{b}}$ & $1 \times 10^{7}$ & 0 & 0 \\
\hline
\end{tabular}

Diluted bacteria were transferred to microtiter plates with granules that had been pre-treated with $\mathrm{H}_{2} \mathrm{O}_{2}$ followed by washing with $\mathrm{NaCl}$. After $24 \mathrm{~h}$ or $7 \mathrm{~d}$ incubation for anaerobes, the number (colony-forming units: $\mathrm{CFU}$ ) of surviving bacteria was estimated by determining absorbance at $\mathrm{OD}_{600}$. Values indicate the highest bacterial growth observed based upon 2-3 observations for each bacterial species

${ }^{a}$ All aerobic bacterial species were diluted in microtiter plates starting at $10^{8}$ bacteria $/ \mathrm{ml}$

${ }^{\mathrm{b}}$ All anaerobic bacterial species including Corynebacterium spp. were diluted in microtiter plates starting at $5 \times 10^{8}$ bacteria $/ \mathrm{ml}$

least 90 days. Taken together, although differences in the inhibitory effect by the Ti-peroxy exist between various bacterial species tested in our hands, we conclude that the Ti-peroxy has a powerful effect upon most bacterial species found in post-operative infections after spine surgery.

\section{Bacteria are lysed by Ti-peroxy as revealed by scanning electron microscopy}

To further shed light upon the inhibitory activity of Tiperoxy on bacterial growth, P. aeruginosa and methicillinsusceptible $S$. aureus (MSSA) representing Gram-negative and Gram-positive species, respectively, were subjected to analysis of the ultrastructure by scanning electron microscopy. Interestingly, bacteria, as exemplified by $P$. aeruginosa, were relatively smoothly attached to the surface of Ti (Fig. 1b, c). After 30 min incubation, bacteria started to lyse (Fig. 1d, g), and after further $2.5 \mathrm{~h}$, the majority of both $P$. aeruginosa and $S$. aureus were destroyed and severely damaged (Fig. 1e, h, respectively). The Ti-peroxide was thus very efficient in bacterial killing. 

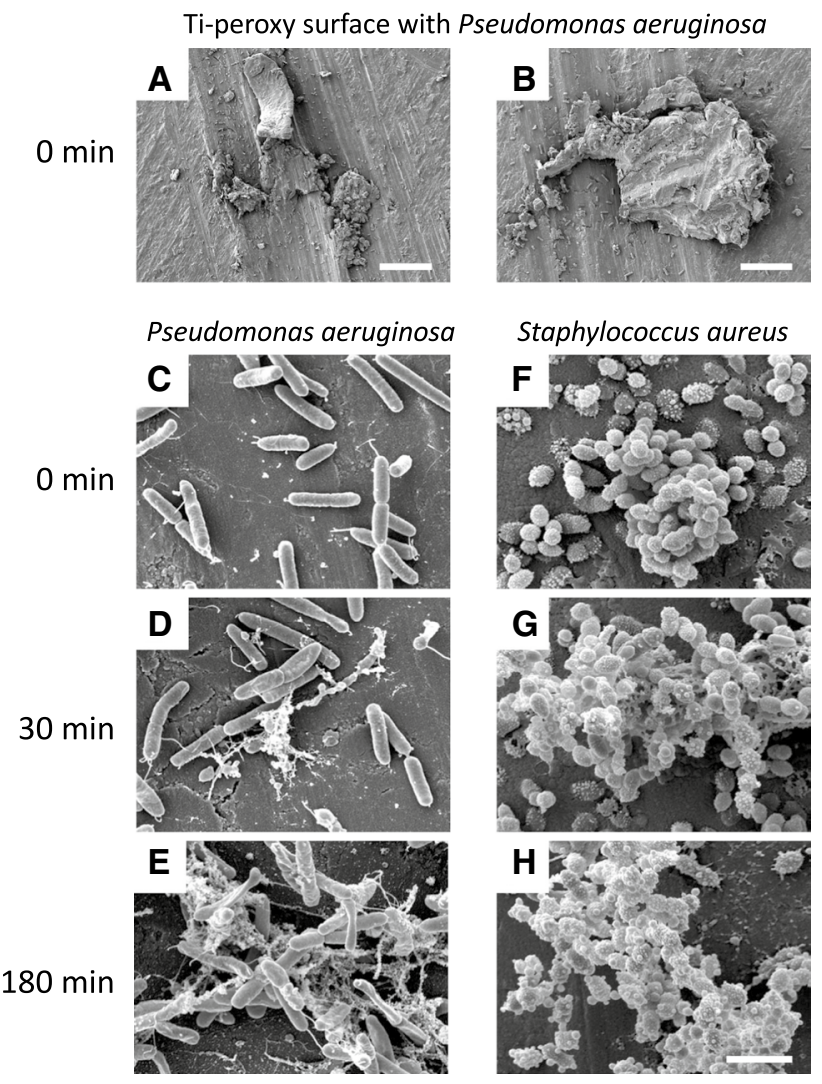

Fig. 1 Pseudomonas aeruginosa and S. aureus are severely damaged in the presence of T-peroxide as shown by scanning electron microscopy. Bacteria were incubated with Ti-peroxy for 0 (a-c and f), $30 \mathrm{~min}$ (d and $\mathbf{g}$ ) and $180 \mathrm{~min}$ (e and h). In panels a-e, representative pictures of $P$. aeruginosa are shown. Staphylococcus aureus has a similar appearance and is illustrated in panels $\mathbf{f}-\mathbf{h}$. Scale bars correspond to the sizes $50 \mu \mathrm{m}(\mathbf{a}), 20 \mu \mathrm{m}$ (b) and $2 \mu \mathrm{m}(\mathbf{c}-\mathbf{h})$. Bacteria were treated with Ti-peroxy for 30 or $180 \mathrm{~min}$. After washing with $\mathrm{NaCl}$, samples were stained with palladium/gold as described in Materials and methods. Finally, samples were subjected to scanning electron microscopy. At the indicated time points, samples were also collected for analysis of bacterial growth. No surviving bacteria were observed at $180 \mathrm{~min}$

\section{Discussion}

In this study, we examined $\mathrm{Ti}$ granules preincubated with $\mathrm{H}_{2} \mathrm{O}_{2}$ forming a Ti-peroxy that was added to both catalasepositive and -negative bacteria of common species that cause deep infections around spinal implants. Catalase is a well-known virulence factor and defence mechanism aimed at neutralizing the oxidative burst consisting of $\mathrm{H}_{2} \mathrm{O}_{2}$. All bacteria were hence inhibited albeit with various efficiencies. Sterile but non- $\mathrm{H}_{2} \mathrm{O}_{2}$-preincubated $\mathrm{Ti}$ granules and also "orthopaedic" stainless-steel granules with or without $\mathrm{H}_{2} \mathrm{O}_{2}$ preincubation were included as controls. Importantly, an inhibition and decreased viability of bacteria were only observed in experiments with $\mathrm{H}_{2} \mathrm{O}_{2}$-preincubated Ti granules (Table 2).
The antibacterial effect of UV treatment of $\mathrm{TiO}_{2}$ is well known [15]. In parallel, RF oxygen plasma treatment of Ti results in an antibacterial effect [16]. The mechanism underlying these bactericidal effects is probably generation and degradation of Ti-peroxy compounds into $\mathrm{H}_{2} \mathrm{O}_{2}$ and oxygen radicals resulting in destruction of bacterial membranes via oxidative processes [15]. The kinetics of these chemical reactions is difficult to determine, and probably the effect of these radical-chemical reactions is present for only a day or two. This presumption is supported by previous degradation experiments with aged and non-aged Ti-peroxy compounds [12]. The Ti-peroxide FT-Raman signal remained detectable in aqueous 3-month-old and dried compounds and in freeze-dried fresh compounds for 3 years. The inhibitory effects on different bacterial species upon incubation with fresh $\mathrm{H}_{2} \mathrm{O}_{2}$-treated Ti granules in the present study are therefore reasonable.

The relatively short period of time with antimicrobial activity may nevertheless be enough to inhibit any hibernating single-cell bacteria before a protective protein coating and/or biofilm is formed. Furthermore, it can be postulated that in the case of deposition of bacteria in the vicinity of implants due to bacteraemia, the biological reaction with recruited inflammatory cells makes a similar formation of Ti-peroxide compound(s) on the surface of Ti implants, possibly enhancing or prolonging the antibacterial effect that would be highly beneficial for the patient.

One interesting observation is that the Ti-peroxy was also effective on catalase-positive species, indicating that the membrane destruction mechanisms are complex and cannot easily be eradicated by catalase. However, since E. faecalis is catalase negative, it was also 10-100-fold more susceptible as compared to the other bacterial species examined (Table 2).

When we have encountered skin perforation due to progressive deformity or trauma in a clinical setting, we have been able to prevent infections by partial implant removal and local $\mathrm{H}_{2} \mathrm{O}_{2}$ treatment in conjunction with parental treatment with antibiotics over a short period of time. This has been successful with Ti-alloy in relation to stainless steel or CrCo implants (Ohlin et al. unpublished data 2007-2014). Based on these observations, we now routinely expose our titanium implants to $\mathrm{H}_{2} \mathrm{O}_{2}$ prior to implantation.

Studies published aiming at predicting risks of unfavourable results in spine surgery, all lack information of which alloy the metal work used was made from and therefore they are not informative in this regard [17, 18]. On the contrary, there is one clinical series published comprising a limited number of patients in which revision due to late infected stainless steel to a titanium-based implants in one surgery was used, with full success in 10/10 cases, supporting our hypothesis in a clinical setting [4]. 
In conclusion, despite relatively large differences existing between the various species tested in this study, we postulate that the Ti-peroxy has a very efficient effect upon most bacterial species irrespective of origin. It should also be emphasized that most likely only single bacteria occur in wounds further increasing the likelihood of preventive antibacterial measures by the Ti-peroxy.

Acknowledgements This work was supported by grants from the Anna and Edwin Berger Foundation, Medical Research Council (Grant Number K2015-57X-03163-43-4, www.vr.se) and Skåne County Council's Research and Development Foundation. We thank Mrs. Allessandro Breda (Pomerton, Maerne [Venice], Italy) for providing us with control granules.

\section{Compliance with ethical standards}

Conflict of interest The authors declare that they have no competing interests.

Open Access This article is distributed under the terms of the Creative Commons Attribution 4.0 International License (http://creativeco mmons.org/licenses/by/4.0/), which permits unrestricted use, distribution, and reproduction in any medium, provided you give appropriate credit to the original author(s) and the source, provide a link to the Creative Commons license, and indicate if changes were made.

\section{References}

1. Abdul-Jabbar A et al (2013) Surgical site infections in spine surgery. Spine 38:E1425-E1431

2. Boody B et al (2015) Surgical site infections in spinal surgery. J Spinal Disord Tech 28:352-362

3. Clark CE, Shufflebarger HL (1999) Late-developing infection in instrumented idiopathic scoliosis. Spine 24:1909-1912

4. Muschik M, Luck W, Schlenzka D (2004) Implant removal for late-developing infection after instrumented posterior spinal fusion for scoliosis: reinstrumentation reduces loss of correction. A retrospective analysis of 45 cases. Eur Spine J 13:645-651
5. Wåxnäs T, Hasserius R, Ohlin A (2012) Implant associated late developing infection after posterior spinal surgery, presented at SRS 47th annual meeting, Chicago, IL

6. LaGreca $\mathbf{J}$ et al (2014) Bacteriology and risk factors for development of late (greater than one year) deep infection following spinal fusion with instrumentation. Spine Deform 3:186-190

7. Di Silvestre M, Bakaloudis G, Lolli F, Giacomini S (2011) Latedeveloping infection following posterior fusion for adolescent idiopathic scoliosis. Eur Spine J Suppl 1:S121-S127

8. Tengvall P, Lundström I (1992) Interaction between hydrogen peroxide and titanium: a possible role in the biocompatibility of titanium. Clin Mater 9:115-134

9. Tengvall P, Hörnsten EG, Elwing H, Lundström I (1990) Bactericidal properties of a titanium-peroxy gel obtained from metallic titanium and hydrogen peroxide. J Biomed Mater Res 24:319-330

10. Tengvall $P$ et al (1990) Degradation of Ti-peroxy gels made from metallic titanium and hydrogen peroxide. J Colloid Interface Sci 139:575-580

11. Mueller S, Arnhold J (1995) Fast and sensitive chemiluminiscence determination of $\mathrm{H}_{2} \mathrm{O}_{2}$ concentration in stimulated human neutrophils. J Biolumin 10:229-237

12. Tengvall P, Vikinge TP, Lundström I, Lieberg B (1993) FT-Raman spectroscopic studies of the degradation of titanium peroxy gels made from metallic titanium and hydrogen peroxide. J Colloid Interface Sci 160:10-15

13. Aubin GG et al (2017) Interaction of cutibacterium (formerly propionibacterium) acnes with bone cells: a step toward understanding bone and joint infection development. Sci Rep 7:42918

14. Riesbeck K, Sanzén L (1999) Destructive knee joint infection caused by Peptostreptococcus micros: importance of early microbiological diagnosis. J Clin Microbiol 37:2737-2739

15. Foster HA, Ditta IB, Varghese S, Steele A (2011) Photocatalytic disinfection using titanium dioxide: spectrum and mechanism of antimicrobial activity. Appl Microbiol Biotechnol 90:1847-1868

16. Monetta T, Belluci F (2014) Strong and durable antibacterial effect of titanium treated in RF oxygen plasma: preliminary results. Plasma Chem Process 34:1247-1256

17. Farshad $\mathrm{M}$ et al (2018) Risk factors for perioperative morbidity in spine surgeries of different complexities: a multivariate analysis of 1,009 consecutive patients. Spine J. https://doi.org/10.1016/j. spinee.201802.003 (E-pub ahead of print)

18. Tsubouchi $\mathrm{N}$ et al (2017) Risk factors for implant removal after spinal surgical site infection. Eur Spine J. https://doi.org/10.1007/ s00586-017-5294-1 (E-pub ahead of print)

\section{Affiliations}

\section{Acke Ohlin $^{1} \cdot$ Emma Mattsson $^{2} \cdot$ Matthias Mörgelin $^{3} \cdot$ Julia R. Davies $^{4} \cdot$ Gunnel Svensäter $^{4} \cdot$ Stéphane Corvec $^{5,6}$. Pentti Tengvall ${ }^{7} \cdot$ Kristian Riesbeck $^{2}$ (1)}

1 Dept. of Orthopaedics, Department of Clinical Sciences, Faculty of Medicine, Lund University, Jan Waldenströms gata 35, 20502 Malmö, Sweden

2 Clinical Microbiology, Department of Translational Medicine, Faculty of Medicine, Lund University, Jan Waldenströms gata 59, 20502 Malmö, Sweden

3 Section of Infectious Medicine, Dept. of Clinical Sciences, Lund University, Lund, Sweden

4 Department of Oral Biology, Faculty of Odontology, Malmö University, Malmö, Sweden
5 Bacteriology and Hygiene Unit, CHU NANTES, Nantes, France

6 CRCINA, INSERM, Université d'Angers, Université de Nantes, Nantes, France

7 Sahlgrenska Academy, Dept. of Biomaterials, Institute of Clinical Sciencies, University of Gothenburg, Göteborg, Sweden 